\title{
A Case of Myasthenia Gravis and Polymyositis developed in Systemic Lupus Erythematosus Patient and Managed by Rituximab
}

\section{Rihab Mohammed Hassan Ali ${ }^{1,2}$, Mohammed Elmujtba Adam Essa ${ }^{3 *}$ Wafa Hassan Ahmed ${ }^{1}$, Noha Ibrahim Ahmed Eltahir ${ }^{1,4}$, Ziryab Imad Taha $^{1,3,5}$, Abdelkareem A Ahmed ${ }^{6 *}$, Ayman Sati Sati Mohamed ${ }^{3}$, Sulafa Eisa Mohammed Ibrahim ${ }^{8}$, Elnour Mohammed Elagib ${ }^{1,4}$}

${ }^{1}$ Department of Rheumatology, Sudan Medical Specialization Board, Khartoum, Sudan ${ }^{2}$ Department of Medicine, Faculty of Medicine, University of Science and Technology, Khartoum, Sudan ${ }^{3}$ Department of Clinical Medicine, Medical and Cancer Research Institute (MCRI), Nyala, Sudan ${ }^{4}$ Department of Rheumatology, Omdurman Military Hospital, Khartoum, Sudan ${ }^{5}$ Department of Medicine and Rheumatology, Faculty of Medicine, University of Bahri, Khartoum, Sudan

${ }^{6}$ Department of Physiology and Biochemistry, Faculty of Veterinary Science, University of Nyala, Nyala, Sudan

${ }^{7}$ Department of Biochemistry Institute of Molecular Biology, University of Nyala, Nyala, Sudan

*Corresponding Author: Mohammed Elmujtba Adam Essa Adam, Department of clinical medicine, medical and cancer research Institute (MCRI), Nyala, Sudan

E-mail: awadali818@yahoo.com

DOI: $10.31080 /$ ASWH.2020.02.0072
Received: November 21, 2019

Published: January 03, 2020

(C) All rights are reserved by Mohammed

Elmujtba Adam Essa., et al.

\begin{abstract}
Systemic lupus erythematosus (SLE), myasthenia gravis (MG) and polymyositis (PM) are three autoimmune diseases that have upper incidence in young women, SLE, MG and PM are three different clinical syndromes which can be coexist or precede each other's, although their occurrence and presence in the same patients are uncommon and rare. The aims of this study are to report the first association of the three immunological diseases in a single patient. Here we report a 36 years old lady with confirmed SLE and on hydroxychloroquine (HCQ) and tapered steroid, 20 months later developed MG, then Creatine Kinase (CK), nerve conduction studies (NCS) and electromyography (EMG) relieved the diagnosis of PM. The patient received four dosages of intravenous immunoglobulin but developed allergic reactions, then rituximab been administrated and all the complained symptoms resolved and the patient returned to her normal daily activities.

Keywords: Systemic Lupus Erythematosus; Myasthenia Gravis; Polymyositis; Rituximab
\end{abstract}

\section{Introduction}

SLE is an autoimmune disease affecting predominantly the young female with no predilection to involve particular organs [1], MG is an organ-specific autoimmune disease characterized by the presence of autoantibodies leads to dysfunction of the neuromuscular junction [2], PM is an inflammatory disorder involves the skeletal muscles and heart in some cases [3].

The global reported prevalence of SLE among the population is $2-15$ cases $/ 10,000[4,5]$, the epidemiology of SLE in many parts of developing countries are still undetermined [6], in black Africans, the incidence of SLE is negligible [7]. In Sudan, lots of SLE can be missed or lately diagnosis due to many reasons include low recognition of the disease at primary points, inadequate numbers of a rheumatologist and limited diagnostic tools, SLE can present separately or with others, auto-immune disease Such as Antiphospholipid syndrome [8], Coexistence of SLE with MG is considered a rare phenomenon, yet sporadic clinical cases recently had been reported [9]. This aim of this study is to increase the knowledge and kindle awareness of this association in Sudan.

\section{Case Report}

36 years old single female, working as a tailor was seen in the out-patient clinic in March 2016. Her main complaints were fatigue, bilateral symmetrical swelling and pain in the small joints of hands and wrists, multiple oral ulcers, which were intermittent and re- 
curing. There were also photosensitive rash and marked hair loss. A diagnosis of Systemic Lupus Erythematosus was made based on serological tests which include positive Anti-double stranded DNA (Anti-dsDNA), positive anti-smith antibodies and low complement 3 and 4 (C3, C4) (Table 1). The patient then received hydroxychloroquine (HCQ) $200 \mathrm{mg}$ once daily and tapered steroid and showed good response. Twenty months later exactly on 25 December 2017 She presented with progressive severe weakness. And this time the patient was unable to claim stairs or rise from the chair, Then the patient developed a double vision in the right eye on looking at all direction. In addition to difficulties in raising her head out of the bed, her sister noticed a drooping of her eyelids in the evenings. The examination revealed normal vital signs, pulse rate 80 beats per minute, regular blood pressure $120 / 70$, respiratory rate of 12 / min. chest, cardiovascular and abdominal examination was unremarkable, neurological examination revealed; normal higher cerebral functions, normal cranial nerves examination, no meninges, eye examination showed positive fatigue ability test, weakness in neck flexion, proximal myopathy in both upper and lower limbs, power grade 2 proximally, distally grade 4 with normal reflexes and all modalities of sensation is intact. The following investigation was done: CK enzyme, acetylcholine receptors antibodies (Table 2), electromyography (EMG), Computed tomography (CT) of the chest, and chest X.ray (Figure 1). HCQ was stopped, because of it is myopathy effect, pyridostigmine was started at a dose of $600 \mathrm{mg}$ every 6 hourly and she continued on mycophenolic acid due to her SLE. Soon a while the patient showed marked improvement in terms of proximal myopathy and the diplopia disappeared, she returned back to her normal life. Seven months letter on the second of July 2018 the patient admitted again to hospital with a severe chest infection, pneumonia diagnosis was made, and received intravenous antibiotics, but at the same time she developed severe generalized weakness, she was unable to get out of bed associated with difficulties in swallowing in spite of no ocular signs or dyspnea on other Bulber signs. Creatine Kinase (CK) enzyme was $6000 \mathrm{U} / \mathrm{L}$, NCS and electromyography (EMG) revealed electrophysiological Findings consist of chronic polymyositis (Figure 2). According to the following clinical features and investigations, a diagnosis of polymyositis was made on top of SLE, and myasthenia gravis. The patient received IVIG $0.4 \mathrm{mg} / \mathrm{kg} /$ day and stopped at the fifth dose when the patient developed an skin rash to it. Added to his low response with sustained weakness and dysphagia. Six months later exactly on January 2019 patient started on rituximab $500 \mathrm{mg}$ I.V (flat dose), she received 3 doses 2 weeks apart, CK enzymes were markedly decreased and other investigations such as Serum glutamic pyruvic transaminase (ALT), Serum glutamic pyruvic transaminase (AST), Creatinine was all normal (Table 3). Now the patient showed marked improvement in terms that can walk without any supported and continue with her daily activities.

\begin{tabular}{|l|c|c|}
\hline \multicolumn{1}{|c|}{ Test } & Result & Ref value \\
\hline Complement C3 & 43.8 & $75-135 \mathrm{Mg} / \mathrm{dl}$ \\
\hline Complement C4 & 5.5 & $9-36 \mathrm{mg} / \mathrm{dl}$ \\
\hline IgA level & 386 & $83-406 \mathrm{mg} / \mathrm{dl}$ \\
\hline IgM Level & 143 & $40-230 \mathrm{mg} / \mathrm{dl}$ \\
\hline IgG level & 651 & $700-1600 \mathrm{mg} / \mathrm{dl}$ \\
\hline Total IgE level & 177 & above 16 years $100 \mathrm{IU} / \mathrm{ml}$ \\
\hline
\end{tabular}

Table 1: Lab investigations and findings supported the diagnosis of SLE.

\begin{tabular}{|l|c|c|}
\hline \multicolumn{1}{|c|}{ Test } & Result & Ref value \\
\hline $\begin{array}{l}\text { Creatine Kinase } \\
\text { enzymes (CK) }\end{array}$ & 4866 & $26-192 \mathrm{U} / \mathrm{L}$ \\
\hline $\begin{array}{l}\text { acetylcholine } \\
\text { receptors antibodies }\end{array}$ & 0.6 & $<0.4 \mathrm{nmol} / \mathrm{l}$ Negative \\
\hline & & $>0.4-<0.5 \mathrm{nmol} / \mathrm{l}$ Borderline \\
\hline & $>0.5 \mathrm{nmol} / \mathrm{l}$ positive \\
\hline
\end{tabular}

Table 2: Lab investigations and findings of the patients.

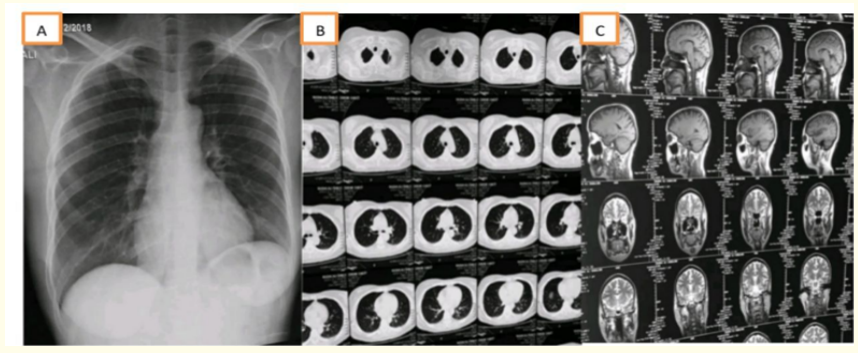

Figure 1: Imaging of chest X.ray (A), CT chest (B), and brain MRI(C) of the patient and all were unremarkable.

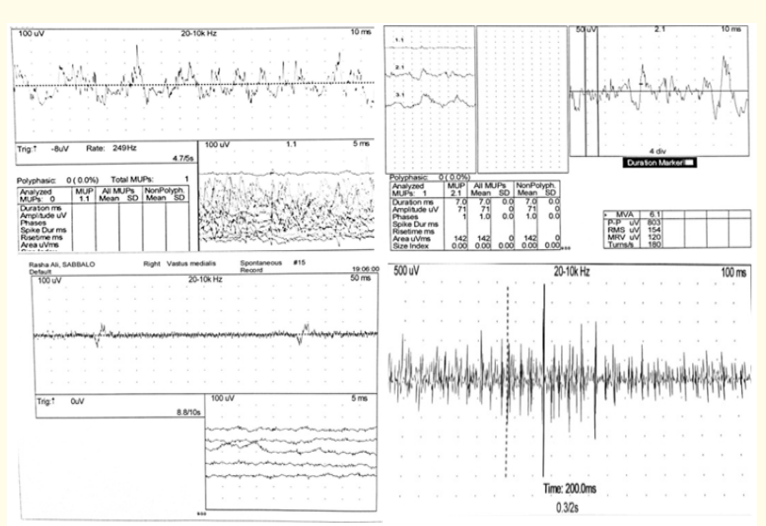

Figure 2: NCS and EMG done to the patient and revealed finding consistent with chronic polymyositis. 


\section{Discussion}

SLE is a multi-organ autoimmune disease involving heart, lung, kidneys and the nervous system [1]. Thirty per cent of SLE patients can be combined with other autoimmune diseases such as antiphospholipid disease [8] and Sjogren's syndrome[10]. MG is characterized by proximal muscle weakness and fatigue, due to damage of acetylcholine receptors at the neuromuscular junctions [11]. Polymyositis is classified as idiopathic inflammatory myopathies [12], occurring as isolated disease or overlap syndrome as SLE. The prevalence of MG in SLE is 1.3\% [11], however, no reported prevalence of cases was found in literate in regard to the combination of the three autoimmune diseases. The diagnosis of MG is primary a clinical-based [13], Fatigue, muscle weakness and ocular weakness resulting in diplopia and ptosis are the main clinical characteristics [14], In our presenting patient the presence of generalized body weakness and ocular symptoms even after the HCQ treatment and NCS findings suggestive the diagnosis of MG.

There are many suggested hypothesis for SLE and MG association which includes; loss of fundamental tolerance after thymectomy subsequent in polyclonal B-cell activation with T-cell lymphopenia and antibodies production, the second hypothesis linked with the structural similarity and molecular mimicry between the central immunogenic region of alpha 65 to 80 of U1 small nuclear ribonucleoprotein and AchR, the third hypothesis is the functional defect of the T-cells in the thymus gland, dysregulated expression of CD95 in both MG and SLE are also one of the proposed hypothesis [15-20]. Chest X.ray and CT chest were done to the patient and shows no thymus abnormalities (Figure 1).

PM, is one of the most common subtypes of idiopathic inflammatory myopathies along with inclusion body myositis and dermatomyositis [21], PM patients presenting with muscle weakness [3], extra muscular manifestations such as arthritis, arthralgia and dysphagia may also occur in thirty per cent of the patients [22], diagnosis of PM depends on the pathological features and clinical investigation such as elevated CK enzyme which is the most commonly performed enzyme test used to diagnose PM [23], muscle biopsy and EMG are also used to confirm the diagnosis [24], the presenting patient complained from weakness in the neck and proximal myopathy in both upper limbs which is considered the hallmark clinical diagnosis of PM [21] and dysphagia as extra-muscular features, CK enzyme to the patients was highly elevated (Table 2), EMG shows features suggest the diagnosis of PM, regarding the muscle biopsy the patient refused the procedure and was not taken.

Myositis is an unusual complication of SLE [25,26], it is reported to occur in near 4 to $16 \%$ of SLE cases worldwide [27], and in Africa occur in 3,4\% [28], the development of PM in SLE patients are believed is related to many aspects such as genetics, environmental and hormonal factors [29]. Some authors also believe that in spite of the sides effects of steroids but the long term use of prednisolone and immunosuppression may reduce the risk of developing PM is SLE patients [30].

We believe this is the first report case of an overlap SLE with MG and PM in one African patient.

\section{Conclusion}

This is a rare presented case of a young Sudanese woman with SLE accompanied by MG and PM treated by rituximab. Association between SLE, MG and PM is complex. In SLE patient any clinical features or serological suspicion of SLE should be evaluated carefully. In Lupus patients with complaining of upper proximal myopathy along with muscle weakness and fatigability, the MG and PM should be ruled out.

\section{Patient Consent}

All authors declare and certify that they have obtained patient consent forms.

\section{Financial Support}

None.

\section{Conflicts of Interest}

All authors declare there are no conflicts of interest.

\section{Bibliography}

1. Nagarajan M., et al. "Systemic Lupus Erythematosus and Myasthenia Gravis: A Rare Association". Indian Journal of Nephrology 29.1 (2019): 62-64.

2. Zhang B., et al. "Autoantibodies to lipoprotein-related protein 4 in patients with double-seronegative myasthenia gravis". Archives of Neurology 69.4 (2012): 445-51.

3. Mozo L., et al. "A case of polymyositis associated with the presence of anti-proliferating cell nuclear antigen antibodies, a marker typically considered SLE specific". Lupus 19.8 (2010): 1002-1003.

4. Pons-Estel GJ., et al. "Understanding the epidemiology and progression of systemic lupus erythematosus". Seminars in Arthritis and Rheumatism 201039.2 (2010): 257-268.

5. Chakravarty EF., et al. "Prevalence of adult systemic lupus erythematosus in California and Pennsylvania in 2000: estimates obtained using hospitalization data". Arthritis and rheumatism 56.6 (2007): 2092-2094.

6. Tiffin N., et al. "Lupus in Africa: Can we dispel the myths and face the challenges?" Lupus (2013): 23. 
7. Kumar K., et al. "Challenges of ethnicity in SLE”. Best Practice and Research Clinical Rheumatology 23.4 (2009): 549-561.

8. Elagib E., et al. "Catastrophic Antiphospholipid Syndrome in Combination with SLE Treated by Rituximab: A Case Report and Literature Review". Lupus: Open Access 4 (2019): 137.

9. Sîrbu E., et al. "Systemic lupus erythematosus followed by myasthenia gravis: a rare association". Central European Journal of Medicine 8.6 (2013): 799-802.

10. McDonagh JE and Isenberg DA. "Development of additional autoimmune diseases in a population of patients with systemic lupus erythematosus". Annals of the Rheumatic Diseases 59.3 (2000): 230-232.

11. Castrejón I., et al. "Association between myasthaenia gravis and systemic lupus erythematosus: three case reports and review of the literature". Scandinavian Journal of Rheumatology 40 (2011): 486-490.

12. Song J., et al. "Meta-Analysis of Polymyositis and Dermatomyositis Microarray Data Reveals Novel Genetic Biomarkers". Genes 10.11 (2019).

13. Pasnoor M., et al. "Diagnosis of Myasthenia Gravis". Neurologic clinics 36 (2018): 261-274.

14. Mustafa MS., et al. "Delayed Diagnosis of Atypical Presentation of Myasthenia Gravis". European journal of Case Reports in Internal Medicine 5.2 (2018): 000785.

15. Hostmann A., et al. "Peripheral B cell abnormalities and disease activity in systemic lupus erythematosus". Lupus 17.12 (2008): 1064-1069.

16. Kigawa N., et al. "Development of myasthenia gravis in systemic lupus erythematosus". European Journal of Case Reports in Internal Medicine 1 (2014).

17. Banica L., et al. "Quantification and molecular characterization of regulatory T cells in connective tissue diseases". Autoimmunity 42.1 (2009): 41-49.

18. Casado E., et al. "Antimalarial myopathy: an underdiagnosed complication? Prospective longitudinal study of 119 patients". Annals of the Rheumatic Diseases 65 (2006): 385-390.

19. Mai W., et al. "Up-regulated expression of Fas antigen in peripheral $\mathrm{T}$ cell subsets in patients with myasthenia gravis". Clinical and Investigative Medicine 35.5 (2012): E294.

20. Mahmoud ZIT., et al. "The role of hydroxychloroquine as monotherapy in managing early undifferentiated arthritis: a prospective hospital-based study". Global Journal of Public Health Medicine 1 (2019): 52-62.
21. Ungprasert P., et al. "Clinical features of inflammatory myopathies and their association with malignancy: a systematic review in Asian population". ISRN Rheumatology (2013).

22. Tomasová Studýnková J., et al. "The role of MRI in the assessment of polymyositis and dermatomyositis" (2007).

23. Volochayev R., et al. "Laboratory Test Abnormalities are Common in Polymyositis and Dermatomyositis and Differ Among Clinical and Demographic Groups". The Open Rheumatology Journal 6 (2012): 54-63.

24. Yang F., et al. "Electrophysiological and clinical examination of polymyositis: a retrospective analysis". The American Journal of the Medical Sciences 348.2 (2014): 162-166.

25. Garton MJ and Isenberg DA. Clinical features of lupus myositis versus idiopathic myositis: a review of 30 cases". British Journal of Rheumatology 36 (1997): 1067-1074.

26. Kilani B., et al. "Association of systemic lupus erythematosus and dermatopolymyositis". La Tunisie medicale 83 (2005): 230-232.

27. Rostic G., et al. "Systemic lupus erythematosus and dermatomyositis--case report". Srpski arhiv za celokupno lekarstvo 133 (2005): 137-140.

28. Maazoun F., et al. "Systemic lupus erythematosusmyositis overlap syndrome: report of 6 cases". Clinics and Practice 1.4 (2011): e89.

29. Liang Y., et al. "Associated Variables of Myositis in Systemic Lupus Erythematosus: A Cross-Sectional Study". Medical Science Monitor: International Medical Journal of Experimental and Clinical Research 23 (2017): 2543-2549.

30. Levine TD. "Rituximab in the treatment of dermatomyositis: an open-label pilot study". Arthritis and Rheumatism 52.2 (2005): 601-607.

\section{Assets from publication with us}

- Prompt Acknowledgement after receiving the article

- Thorough Double blinded peer review

- Rapid Publication

- Issue of Publication Certificate

- High visibility of your Published work

Website: https://www.actascientific.com/

Submit Article: https://www.actascientific.com/submission.php Email us: editor@actascientific.com

Contact us: +919182824667 